\title{
О ТЮРКСКОЙ СОСТАВЛЯЮЩЕЙ В МИРОВОЙ КУЛЬТУРЕ И ЦИВИЛИЗАЦИИ
}

Булекбаев С. Б.

д. филос. н., профессор, Казахский Университет Международных Отношений и Мировых Языков имени Абылай Хана sagadi58@mail.ru

Айдарбеков 3.С. д. филос. н., профессор Казахский Университет Международных Отношений и Мировых Языков имени Абылай Хана

\section{Аннотация}

Тюркский мир на протяжении длительной истории являлась уникальным местом, где зарождались и развивались мощнейшие культуры и цивилизации, оказавшее огромное влияние и воздействие на ход, и развитие мировой истории, культуры и цивилизации. Его влияние было обусловлено тем, что Тюркский мир, будучи географически расположенный в центральной части евразийского континента, всегда был связующим мостом между двумя великими культурами Востока и Запада.

Ключевые слова: Тюркский мир, культура, цивилизация

\section{ABOUT TURKIC COMPONENT OF WORLD CULTURE AND CIVILIZATION}

\section{Abstract}

Throughout its long history, the Turkic world has been a unique place where powerful cultures and civilizations originated and developed, which had a huge impact on the course and development of world history, culture and civilization. Its influence was due to the fact that the Turkic world, being geographically located in the central part of the Eurasian continent, has always been a connecting bridge between the two great cultures of the East and West.

Keywords: Turkic world, culture, civilization 
И то, что это месторасположение тюрков, с одной стороны вполне закономерно обуславливало, неизбежное влияние и воздействие этих великих культур на тюркскую, что естественно приводило к усвоению и заимствование некоторых элементов этих культур, а, с другой, и тюрки имели свою, и достаточно высокую для своего времени культуру и цивилизацию. Более того, их культура, как показывают объективные не зашоренные различными центризмами исследования, оказывала огромное влияние и воздействие на соседние, часто задавая, по мнению многих выдающихся ученых, стартовые условия для развития соседних цивилизаций, в частности, на российскую и европейскую.

Для обоснования этого тезиса, наметим некоторые подходы, которые, с нашей точки зрения, позволяют более четче и аргументированней обозначить, во-первых, место и роль тюрков в мировой истории, во-вторых, их вклад в мировую культуру и цивилизацию, а в-третьих, отметить, что казахи, как часть тюркского народа по историческому праву занимает свою законную нишу и подобающее место в тюркской истории. Здесь имеется в виду то, что казахи, как народ, исторически проживающий в Великой Степи, в центре Евразии, где в основном начинались и вершились важнейшие исторические события, часто менявшие ход мировой истории, был всегда одним из основных субъектов великой тюркской истории. Отсюда история казахов неотделима от тюркской истории. Поэтому наша история должна рассматриваться и изучаться как история тюрков и казахов. Последние по праву должны разделять как исторические успехи, так и поражения своих предков тюрков.

История тюрков, как известно, начинается с V века. C эпохи Тюркских каганатов, которые, согласно Л. Гумилеву, стало в какой-то мере переломным

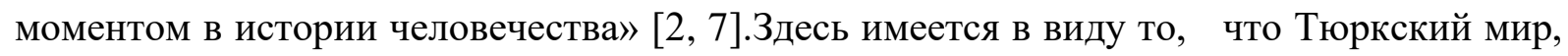
контролируя огромную территорию между Востоком и Западом, всегда был тем мостом, который на базе Шелкового пути, проходящий через ее огромную территорию, связывал культуры и цивилизации Востока и Запада. Это стало возможным лишь в конце VI века, поскольку именно тогда границы тюркского каганата сомкнулись на западе с Византией, на юге с Персией и даже Индией, а на востоке с Китаем. Ввиду этого обстоятельства история соседних государств в этот период была связана с судьбой тюркской державы. Образование тюркского каганата, 
стало в какой - то мере переломным моментом в истории человечества, потому что до этих пор средиземноморская и дальневосточная культуры были разобщены, хотя и знали о существовании друг друга. Бескрайние степи и горные хребты препятствовали сношениям Востока и Запада. Только позднее изобретение металлических стремян и вьючной упряжи, заменившей телеги, позволило караванам сравнительно легко форсировать пустыни и перевалы. В этой ситуации тюрки сыграли роль посредников между Востоком и Западом. Эта связь осуществлялась не только на базе Шелкового Пути, но и на базе разносторонних экономических, политических, культурных, военных, международных и других связей с пограничными государствами [2, 7]

Вполне соглашаясь с тем, что тюркский мир был тем мостом, который соединял две великие культуры Востока и Запада, вполне признавая их влияние и воздействие на тюркскую, на мой взгляд, многие исследователи, почему-то не указывают на то, что тюрки имели свою, вполне самостоятельную и вполне самодостаточную культуру и цивилизацию. Отмечая самобытность тюркской культуры, которая возникла и существовала независимо от культур Ирана и Китая Л. Гумилев писал: «Пора прекратить рассматривать народов Центральной Азии только как соседей Китая и Ирана. Надо, наконец, сделать практический вывод из того бесспорного положения, что их история и культура развивались самостоятельно. Только так можно понять, как они жили, чувствовали, торжествовали и погибали»[3.]. Более того тюрки, именно в центре Евразии, сами создали несколько очагов мировой культуры и цивилизации, которые оказали существенное влияние и на другие культуры и цивилизации, в первую очередь европейскую. Задав, как справедливо говорят многие известные ученые, в частности, как Джавахарлал Неру, Вернадский В. И, ей стартовые условия развития.

Суть заданных стартовых условий заключается в том, что тюрки привнесли с собой более высокие для того времени образцы и элементы культуры. Особо здесь следует отметить переход от века камня и бронзы к веку железа. Он пришелся на V- III века до новой эры. Это событие отмечено приходом к тюркам нового Бога - Тенгри хана. Он научил людей плавить железную руду. Началась новая эпоха в жизни не только алтайских, но и других народов. Железо - металл древний. Он был знаком и египетским фараонам. Железо добывали и на Кавказе и в Малой Азии. Только с тем различием, что здесь его не выплавляли, а выжигали, получая так называемое «кричное

Year 4/ 2020, Volume-4, Issue-1 | WWW.ispecjournal.org 
железо», пригодное для ковки. Что касается алтайских тюрков, то они придумали свою технологию, которая используется во всем мире поныне. Они додумались железную руду не выжигать, а плавить в горнах, последовательно получая чугун и сталь. Это давало колоссальную выгоду и увеличивало выход металла. Между прочим, «чугун» тюркское слово, «булат» - тоже. Они памятники той далекой поры, когда началась новая эра в истории человечества. Железо в руках тюрков уже не было драгоценностью, как у египетских фараонов, оно превратилось в рабочий металл. Согласно Л. Гумилеву, хотя «железо и раньше было известно кочевникам, но только тюркюты ввели его, а массовое употребление. Он отмечает, что когда известный Земарх, увидев тюркютов, предлагающих ему железо для продажи, был чрезвычайно удивлен и заподозрил, что это делается нарочно, чтобы дезориентировать его: «ибо обыкновенно говорят, что у них трудно достать железо».

Здесь нужно отметить, что тюрки не только сумели организовать массовое производство железа, но и то, что их сыродутное железо содержало, по мнению специалистов, до 99,45 \% чистого металла и поэтому было весьма ковким и прочным. Из высококачественного железа кочевники-кузнецы изготовляли однолезвийные ножи, тесла-топоры, стремена, удила, мечи, сабли с малым изгибом и массивным клинком, наконечники копий и стрел, железные котлы двух типов: круглые - подвесные и стоячие - на конической ножке. Развитие металлургии позволило тюркским каганам перевооружить свою армию и создать отборные, ударные части из латной кавалерии фули (т.е. «волки» - «бури» - названные так «в память» своего мифического происхождения от волчицы). На их вооружении были роговые луки, панцири, копья, сабли и палаши.

Таким образом, как утверждают археологические и письменные источники, и ранее, и в эпоху средневековья кочевники выступили на арену мировой истории как народ, впервые освоивший в Степях Центральной Азии промышленную добычу железа и благодаря этому поставивший себя в независимое положение по отношению к Китаю и Тибету, откуда до этого времени кочевники получали железное оружие необходимое для успеха их военных предприятий [3].

На наш взгляд, Мурат Аджи совершенно прав, когда говорит, что созданная тюрками технология получения железа на основе плавки железной руды в горнах, значительно увеличившая добычу металла по сравнению с традиционным выжигом

Year 4/ 2020, Volume-4, Issue-1 | WWW.ispecjournal.org 
металла, и поэтому вполне может оцениваться как научно-техническая революция. В дальнейшем, это открытие, совершенное тюрками на Алтае, со временем распространилось по всему миру, начиная с Китая и Европы [4].

Говоря о тюркском вкладе в мировую цивилизацию, нельзя не привести слова великого русского историка Л. Н.Гумилева, который, споря со своими оппонентами, писал: «Нереально думать, что в кочевом обществе невозможен технический прогресс. Кочевники вообще, а хунну и тюрки в частности, изобрели такие вещи, которые ныне вошли в обиход человека как нечто само по себе подразумевающееся. Первое усовершенствование одежды- штаны- сделаны еще в глубокой древности. Стремя появилось в центральной Азии между 200 и 400гг. Первая кочевая повозка на деревянных обрубках заменилась сначала коляской, а потом вьюком, что позволило кочевникам форсировать горные, поросшие лесом хребты. Кочевниками были изобретены изогнутая сабля, вытеснившая прямой меч, и длинный составной лук, метавшей стрелы на расстоянии до 700 метров. Наконец, круглая юрта в течении времена считалась наиболее совершенным видом жилища [5].

Стартовая позиция для европейской цивилизации была задана культурными достижениями Востока. В этом плане Тюрки в значительной степени содействовали проникновению восточной культуры в Европу. Вернадский обращает в этой связи особое внимание на открытие и распространение книгопечатания, позволяющего в величайшей степени увеличить силу человеческой личности и мысли, фиксируя, сохраняя и передавать из поколения поколение накопленные сведения и знания. С книгопечатания собственно, ведет свое летоисчисление современная научно техническая эпоха. Не позднее VI века в Китае уже практикуется способ печатания с резных деревянных досок. В ХІІІ - ХІУ вв. он проник в Европу и подготовил открытие Гуттенберга. Марко Поло, обратил внимание на печатание в монгольской империи денежных ассигнаций. «Огромное - по выражению Вернадского - всемирноисторическое значение» «монгольского нашествия» состоит в том, что благодаря нему в рамках единого государственного целого соединились «народы различной, нередко очень высокой культуры». Вместе с ксилографическим способом печатания монголы способствовали проникновению в Европу бумаги, гречихи, буровых скважин [6].

К сказанному можно добавить и высказывание выдающегося казахского философа Касымжанов А. Х., который также отмечал, что тюрки в Евразии создали особую 
цивилизацию. Он говорит: «С моей точки зрения, в ландшафтной зоне евразийских степей, в которые входит и территория Казахстана, сформировалась.... особая цивилизация, связанная конечно, с пастбищным скотоводством в силу природных условий, но включающая в себя, помимо этого, технологические и культурные достижения, «конную культуру», плавку железа, города, ремесла, земледелие, в том числе ирригационное искусство. Добавьте к этому образование мировых империй и влияние на мировые миграционные демографические процессы» [7].

На мой взгляд, все должны знать, особенно тюркские народы, что они представители народа, который уже в глубокой древности раньше других освоил дерево и металл, приручил животных. Что эти открытия их предков, по существу, явились научно-техническими революциями для человечества. Что именно благодаря этим открытиям человечество значительно обогатилось и продвинулось вперед в своем развитии. Об этом надо в полный голос говорить и писать.

Раскрывая роль тюрков в мировой истории, нельзя не сказать о том, что Тюрки своими историческими завоеваниями не раз существенно влияли на ход и развитие мировой истории. Отмечая судьбоносную роль тюрков в истории, известный французский философ, Шарль Монтескье писал в своей книге «Персидские письма»: «Ни один народ в мире ... не превзошел татар своей славой или величием своих завоеваний. Этот народ поистине владыка вселенной; все остальные как будто для того созданы, чтобы ему служить, он также основатель и разрушитель империй; во все времена он проявлял на земле свое могущество, во все века он был бичом других народов. Под именем турок они совершили необъятные завоевания в Европе, Азии и Африке; и они господствуют над этими тремя частями света. А если углубиться в более отдаленные времена, то мы увидим, что от них же произошли некоторые из народов, уничтоживших Римскую империю. Что значат завоевания Александра в сравнении с завоеваниями Чингисхана»? [8].

Монтескье прав, действительно, только завоевания Чингисхана значительно превосходят завоевания семи крупнейших европейских полководцев, признанных всем миром - Александра Македонского, Ганнибала, Цезаря, шведского короля Кала XII, Фридриха Великого, А.В.Суворова и Наполеона Бонапарта. Согласно исследованиям монгольского ученого Жадамбына Энхбаяра: «...семь великих полководцев мира завоевали на семерых территорию 6900000 кв. км, в то время как 7

Year 4/ 2020, Volume-4, Issue-1 | WwW.ispecjournal.org 
770000 кв. км были покорены только одним Чингисханом. Таким образом, «ни один из «великолепной семерки» полководцев не идет ни в какое сравнение с Чингисханом и Бату-ханом ни по площади покоренной территории, ни по устойчивости созданного государства, ни по следу, оставленному в истории» [9].

Мы здесь уже не говорим о других великих тюркских полководцах, таких как Бумын кагане, Истеми кагане, Бильге кагане, Культегине, Сулеймане Великолепном, Тамерлане, чьи завоевания не раз меняли ход и вектор мировой истории и мировой политики. Понятно, что эти завоевания существенно влияли на общественное бытие и социальные институты покоренных народов. На это приходиться обращать внимание потому, что многие европоцентристски ориентированные исследователи, сводят завоевания тюрков, с одной стороны, только к грабежу и разорению, а с другой, к оправданию отсталости развития своих стран. Как правило, полностью забывая о том, что любое явление или событие имеет две стороны- хорошую и плохую. Это зависит от точки зрения. Именно обращая внимание на эту сторону, Джавахарлал Неру писал, что тюрки не только «опустошали Европу - но и цивилизировали Европу» [10]. Другими словами, тюркская культура оказала заметное влияние на становление и развитие европейской культуры.

Однако, для того чтобы одна цивилизация оказывать цивилизирующее воздействие на другую, она сама должна быть достаточно развита. В этом плане, вне всякого сомнения, важным достижением тюркской цивилизации, согласно выдающемуся тюркологу С. Максуди является способность тюрков к общественной организации и к созданию государств [11]. Необходимость развития и совершенствования таких институтов было вызвано тем, что во вновь созданных огромных империях, перед тюрками вставала задача - организовывать, управлять и контролировать под своей властью покоренные народы. Это говорит о том, что тюрки должны были совершенствовать свою систему государственного и административного управления. По мнению исследователей, зачастую структура тюркских государств была более совершенной, чем у завоеванных народов. На это приходится обращать внимание потому, что именно на эту стороны исследователи недостаточно уделяют внимание.

Если о завоеваниях и империях тюрков есть более или менее достоверная информация, то о их вкладе в создание общественных и государственных институтов 
известно очень мало, хотя, по мнению Л. Гумилева, тюрки создали для своего времени более сложные и более совершенные формы общественного бытия и социальные институты: эль, удельно-лестничная система, иерархия чинов, кочевая демократия, налоговую систему, денежное обращение, дипломатия, книгопечатание и т.д [12].

Мы здесь полностью согласны с известным тюркологом Р. Рахманалиевым, который говорит, что тюрки «захватив троны трех континентов - в Пекине, Дели, Исфахане, Дамаске, Багдаде, Каире, Константинополе, Алжире, - они должны были действовать так, чтобы не потерять их [13]. А это было возможно лишь в том случае, если могли создать на завоеванной территории управляемую структуру, совершенную систему государственного и административного управления, в частности государственный аппарат, налоговую систему, таможенную службу, наладить торговлю c соответствующей потребностям империи денежное обращение, обеспечить безопасность в стране и торговле. Не говоря о том, что должна быть дипломатическая служба, разведка. Что касается военного искусства, здесь мы имеем в виду военной тактики, стратегии, дисциплины, то в этой области тюрки значительно превосходили другие народы. Кстати военная тактика и стратегия тюрков была взята на вооружение многими армиями мира, в частности русской. Доказательством превосходства военного искусства тюрков могут служить завоеванные тюрками территории и государства. Их завоевания простираются до Тихого и Атлантического океана.

Важнейшим достижением тюркского народа было создание впервые в истории человечества письма, в том числе и алфавитного, основанного на звуковом принципе. Алфавитная письменность дала возможность фиксировать речь по звуковому способу с помощью минимального числа легко и быстро запоминающихся знаков-букв. Находка тюркской письменности была в науке ошеломляющей сенсацией. Эрнст Добльхофер искренне писал: “Они (тюркские письмена - С.Б.) происходят из области, являвшейся для всех западных культур “потусторонним миром”, из самого сердца Азии, и принадлежат народу, о котором мы долгое время совершенно ничего не знали, да и теперь еще знаем чрезвычайно мало, - вот почему они и представляют интерес» [14]. Другое его высказывание: «Мы и сейчас не можем равнодушно относится к языку древнетюркских памятников... Выросший в постоянном общении с древними 
культурными народами этот народ в VI веке стоит на поразительно высокой ступени развития» [14].

Еще один аспект, на которое, на наш взгляд, недостаточно уделяют внимание исследователи тюркской истории. Это то, как и за счет чего тюрки помимо силы власти и управления могли удерживать столь длительное время под своим господством покоренные народы? В чем причины феномена «долговечности» существования огромных тюркских государств, «секреты» их управления огромными империями и многочисленными народами? На мой взгляд, это связано, также и с мировоззренческими основаниями тюрков, точнее, их философией. Как сказано уже в сказании огузов, для тюрков «небо - наш шатер, а солнце - наше знамя». Отсюда они своей родиной считали регионы своего проживания и не рассматривали рядом проживающие общности отдельно от своего этноса. Отсюда проистекает их толерантностью. Тюрки всегда стремились к тому, чтобы заставить самые разные народы жить вместе, в гармонии, оставляя им, правда, под своей централизованной до предела и деспотической властью их идентичность, язык, культуру, религию, а часто и правителей. Их толерантность изначально проистекает из специфики тюркского понятия государства, тюркского управления народами. Взойдя на вершины власти, благодаря праву завоевателя, они не гнушались обращаться за помощью к вассалам, когда те были более цивилизованными, чем они сами, и часто доверяли им важные дела; они также не стеснялись заимствовать у них то, что могло быть полезным: иногда технику, иногда образ жизни, иногда религию или язык. Это объясняет, почему так часто они заканчивали тем, что ассимилировали в покоренных массах [15].

Здесь нужно заметить, что тюркское государство, каким бы большим оно ни было, у ней всегда была цель. Этой целью, уже начиная с орхонских надписей, была провозглашена: безопасность, порядок и справедливость. Иначе говоря, тюрки, стремясь овладеть миром, одной из своих важных целей считали привнесение в него мира, порядка и справедливости. Они обеспечивали это путем налаживания порядка, четкой административной и таможенной системы, безопасной торговли по всей империи и с соседними государствами.

Следует отметить, что на завоеванных землях чаще всего наблюдался невиданный расцвет, к примеру, Китай под властью Табгача, Иран под сельджуками, Египет под мамлюками, Индия под владычеством Великих Моголов; что касается Османской 
империи - то это была одна из крупнейших тюркских держав мира, которая сначала являлась для ислама мечом, затем - щитом.

Нужно отметить, что тюрки привнесли с собой высокую для своего времени не только духовную культуру, но и материальную. Согласно мнению известного тюрколога Р. Рахманалиева, именно при владычестве тюркской династии Вэй в Китае сформировалась одна из лучших скульптурных школ в пещерах Юньгана и Лунмэня; тюрками были созданы самые прекрасные и экспрессивные монументы Азии - большая мечеть Пятницы в Исфахане, мавзолей Ахмету Ясави в Туркестане, Тадж-Махал в Агре, Регистан в Самарканде и мечеть Сулеймана в Стамбуле... [16].

Как видно уже из вышесказанного, достижения тюрков во всех областях культуры и цивилизации весьма внушительны и вряд ли все можно перечесть в одной статье. Мы и не ставим такую задачу. Для нас важно обратить внимание тюркских народов на настоятельную необходимость создания конкретной, вполне осуществимой программы возрождения духовного наследия тюркских народов. Эта программа должна иметь четкий идеологический ориентир позволяющая трезво осмыслить состояние тюркского мира. С точки зрения этой идеологии, на наш взгляд, нужно, в первую очередь возродить тюркское самосознание, тюркскую духовность, ее высокий духовно-нравственный потенциал, то есть создание целостной программы духовного возвышения, а не унижения человека, формируемого современной потребительской цивилизацией запада

Сегодня настало время для возрождения, не востребованных в силу многих причин, тюркской культуры, и настало время понимания того, что общечеловеческая цивилизация представляет собой не только достижение Запада, но и остальной части мира, в том числе и Евразии.

Список используемой литературы:

1.Нарымбаева А. К. Туран - колыбель древних цивилизаций. - Алматы, 2009. - с. 675-676.

2.Цит. По книге Уали М. Тюркские мотивы. Алматы: «Галым», 2009. С.218.

3. География этноса в исторический период. Л., 1990. С. 279.

4. Мурат Аджи. С. Азиатская Европа. - М.: АСТ МОСКВА, 2008. с.190-191.

5. Гумилев Л. Н. Тысячелетия вокруг Каспия. М., 1993. С.86.

Year 4/ 2020, Volume-4, Issue-1 | WwW.ispecjournal.org 


\section{ISSN 2717-7262 ISPEC Journal of Social Sciences \& Humanities}

6. Вернадский В. И. Труды по всеобщей истории науки. 2-е изд., М., 1968, с. 91-92 /. (Из книги Касымжанова А. Х. стр150).

7. Касымжанов А. Х. Самоопределение и духовное наследие// Саясат, март 1999. C. 88 .

8. Монтескье Ш. «Персидские письма»/Перевод с французского под редакцией Гунста Е.А. - Москва: Издательство "ИОЛОС", 1993.

9. (М. 2008 г., изд-во «Идея-пресс»).

10. Цит. по Козыбаев М. К. Казахстан на рубеже веков. С. 49-50.

11. Садри Максуди Тюркская история и право//Казань, Издательство «Фэн»,2002 c. 10

12.Гумилев Л. Н. Древние тюрки / Л. Н. Гумилев. - М.: ООО «Издательство $\mathrm{ACT} », 2004$. c. 7.

13. Рахманалиев Р. Империя тюрков. Великая цивилизация. - М.: РИПОЛ классик, 2009. - 576 c.

14.Эрнст Добльхофер. Знаки и чудеса. - М., 1963. - С. 332-333, 352

15. См. подр. Барманкулов М. Тюркская вселенная. - Алматы: Білім, 1996. с. 182$187 /$

16. Рахманалиев Р. Империя тюрков. Великая цивилизация. - М.: РИПОЛ классик, 2009. - 576 с. 